\title{
PARTIDO VERDE E A NECESSIDADE DE NOVOS ARES COMUNICACIONAIS
}

\author{
Lucas Pereira de Souza', Ana Paula Donaton Ribeiro² \\ Universidade Estadual de Londrina - UEL, Pós-Graduação em Marketing e Propaganda, Londrina, PR. \\ Universidade do Oeste Paulista - UNOESTE, Pós-Graduação em Design Gráfico, Presidente Prudente, SP. E- \\ mail: lucpereirasouza@yahoo.com.
}

\section{RESUMO}

O presente artigo busca entender o processo de comunicação atual do Partido Verde - PV, tendo como base uma metodologia qualitativa, exploratória e bibliográfica. Navegaremos pela construção desse discurso ao longo da história do partido aqui no Brasil. O objetivo é nortear as diretrizes do discurso do partido de acordo com a evolução da população, onde uma mensagem redundante já não funciona com o atual eleitorado. Como resultado deste estudo temos um direcionamento adequado à realidade do país. Assim a disseminação dos valores do PV, que são muito bem-vindas no exterior, podem ser difundidas de modo mais amplo e correto aqui no pais. Palavras-chave: Marketing Verde; Partido Verde; Comunicação.

\section{GREEN PARTY AND THE NEED FOR NEW COMMUNICATIONS}

\begin{abstract}
The present article seeks to understand the process of communication to Current Green Party $\mathrm{PV}$, and as a basis of a qualitative methodology, exploratory and bibliographic. Understanding the construction In this speech Along Party History Here in Brazil. The objective and guide as According Party Speech Guidelines with the Population Evolution, A Where redundant message no longer works with the current electorate use. As a result of this study we have a suitable targeting the Reality of the country. So a dissemination of values to PV, are very welcome abroad, they be broadcast mode more broad and right here in the country.
\end{abstract}

Keywords: Green Marketing; Green Party; Comunication. 


\section{INTRODUÇÃO}

Este estudo é acerca do Marketing Político e Sustentável. Tomamos como base um eleitorado cada vez mais inteligente, mudanças ambientais muito fortes, crises econômicas capazes de transformar estruturas a nível mundial, à vista disso o marketing político se torna necessário parar nortear decisões diante a grandes riscos nos processos políticos.

Segundo Azevedo (2002) "as técnicas eleitorais, como marketing político e eleitoral e as pesquisas, são neutras do ponto de vista político e ideológico". Para a sociedade, entender estes processos compreendidos a partir de um case evita julgar o Marketing como ideologia política e partidária, quando na verdade é apenas uma ferramenta capaz de ajudar na disseminação de informação e promover uma conexão melhor entre candidatos ao governo e a sociedade.

Lipovetsky e Serroy (2011) defendem que a sociedade, mesmo que individualista, estimula a participação social, por isso os processos a cerca da sustentabilidade estão em evidência sendo amplamente usado por empresas como cerne de um negócio, o que pode ser aplicável ao nível político, trazendo o sustentável como posicionamento estratégico de um partido/candidato. Temos então este estudo aplicado a três áreas: Marketing, Política e Sustentabilidade.

A metodologia empregada neste artigo foi a pesquisa bibliográfica e exploratória para entender como se comunicar com o eleitorado e como é feita de uma comunicação mais próxima com o público e o estudo de caso do Partido Verde (PV) para verificar a atual situação do partido no Brasil. O que possibilita a criação de uma comunicação melhor com a população.

\section{MARKETING POLÍTICO}

Kotler e Armstrong (2006) explica que Marketing "envolve a identificação e a satisfação das necessidades humanas e sociais"

Rego, 2002, cita que "Marketing é o conjunto de atividades destinadas a promover relações de troca entre um emissor e um receptor, no momento certo, por meio de canais adequados e mensagens apropriadas que atinjam o foco de interesses dos segmentos alvo." 0 mesmo defende que Marketing político nada mais é que a relação entre o candidato e o eleitor tendo como base de troca promessas e votos. Ele aprofunda ainda ao afirmar que "comunicações, programas, compromissos, promessas, favores constituem o eixo da identidade do candidato. $\mathrm{E}$ esse eixo é transmitido por meio de canais impressos e eletrônicos".

A necessidade desta ferramenta para angariar mais votos surgiu da necessidade da própria sociedade, como explica o autor:

O conflito de interesses, as pressões sociais, a quantidade de candidatos, a segmentação de mercado, as exigências de novos agrupamentos de eleitores, o fortalecimento dos grupos de pressão, a competição desmesurada (...) os novos valores ditados pela indústria cultural e o crescimento vegetativo da população constituem, entre outros, os elemento determinantes da necessidade de utilização dos princípios do marketing aplicados à política. (REGO, 2002, p. 28)

\section{MARKETING VERDE}

Nas últimas décadas, essencialmente após a Rio 92, a preocupação com a preservação ambiental passou a ser crescente não só no Brasil como no mundo. A constatação dos efeitos colaterais da exploração dos recursos renováveis, o acentuamento de crises, o mau gerenciamento do lixo e a discussão por métodos de produções mais limpos, tanto ecológica quanto socialmente, foram crescendo nos debates entre líderes e principalmente entre a própria população. 
O comportamento do consumidor mais consciente, assumindo novas percepções de responsabilidade no consumo, esta levando cada vez mais marcas a utilizarem uma nova estratégia de marketing, levando em consideração aspectos ecológicos, o chamado Marketing Verde.

O marketing verde consiste no "interesse das empresas em desenvolver e comercializar produtos ambientalmente responsáveis" (KOTLER; ARMSTRONG, 2006, p. 546). Apesar dessa abordagem ainda estar em desenvolvimento, existe uma certeza que a consciência sustentável é a premissa para essa e as próximas gerações.

\section{SUSTENTABILIDADE}

O conceito de sustentabilidade começou a ser usado na década de 1970, e até hoje, torna-se uma abordagem de crescente importância para se trabalhar em temas como economia, desenvolvimento social, comercial e ecologia.

A questão, apesar de ser na maioria das vezes usada com sentido ecológico, não trata da autossuficiência apenas nesse sentido. A sustentabilidade é inerente a qualquer desenvolvimento humano, levando em conta a máxima que para ser sustentável, o processo precisa ser economicamente, socialmente, culturalmente e ecologicamente viáveis.

Isso contribuiu para que as marcas passassem a ter preocupações a longo prazo com o bem estar geral, tanto que normas e certificações que garantam esse ajuste das mesmas, atualmente, são extremamente valorizados pela sociedade e público consumidor e a garantia de que uma maquiagem verde não esteja sendo usada ali.

Segundo ainda Evangelista e Ruão:

A sustentabilidade deve ser o guia para qualquer organização e deve tornarse o caminho para uma atuação ética, consistente, eficiente e justa", mostrando que comunicar as práticas sustentáveis de uma organização não deve ser apenas uma 'obrigação' oriunda das demandas de consumidores mais esclarecidos e exigentes. Comunicar a sustentabilidade deve ser antes uma forma de reforçar a imagem e reputação das organizações: "ao fazerem isso, as organizações podem potencializar as suas relações e ter ganhos de imagem e reputação". (EVANGELISTA; RUÃO, 2011, p. 8)

\section{PARTIDO VERDE}

O Partido Verde (PV) surgiu como instituição política na Austrália, por idealização de ecologistas no ano de 1972. Segundo o site oficial do partido no Brasil:

O objetivo inicial era impedir o transbordamento do Lake Pedder. Mais Tarde o grupo adotou o nome de Green Party. [...] Da Austrália para a Nova Zelândia, depois para Europa e hoje em todo o mundo. Com sedes em mais de 120 países, hoje o Partido Verde participa de vários governos e é a quarta maior bancada no Parlamento Europeu. (PARTIDO VERDE, 2016).

Ainda segundo o site, no Brasil, o PV teve inicio de atividades no Paraná em 1982 mas veio a ser oficialmente fundado em 1986 no Rio de Janeiro por um grupo de profissionais que além de ecologistas e ativistas, contava também com ex-exilados políticos, jornalistas e artistas. Ainda em 1986 participou das eleições estaduais, inaugurando no Brasil propostas e manifestações por uma política ecológica e sustentável, recebendo forte oposição dos conservadores da época. Em 1989 participou pela primeira vez de uma campanha presidencial, sendo que em 1990 perdeu o direito de existir legalmente.

Após dois anos, durante RIO-92, seus integrantes promoveram uma reunião entre os Partidos Verdes de outros países, o que o trouxe definitivamente para o circulo político 
nacional e, com tal visibilidade, ajudou-o a eleger cinquenta e quatro vereadores e dois prefeitos no mesmo ano, colaborando para que em 1993 conseguisse o seu registro legal novamente.

Em 1994 elegeu os seus primeiros deputados; 97 com a filiação do Governador do estado do Espírito Santo, o seu primeiro governador; 2000 elegeu 13 prefeitos e 315 vereadores; em 2003, com aliança a base do governo teve um membro do partido como Ministro; 2004, o PV chegou a 55 prefeitos e 773 vereadores em todo o país.

Ainda com relação ao crescimento do partido associado a uma pretensão mais ecológica, no livro comemorativo aos 20 anos do PV de Claudio Turtelli "Trajetória nas Urnas, Uma Análise de Resultados", é possível perceber o desempenho dele em números, nas urnas: de 1994 até 2004 o partido passou de 76 mil votos para quase 3 milhões.

Através do artigo "Partido Verde e o Uso Da Sustentabilidade como Estratégia de Marketing" da autora Maria Fernanda Murad Sarney é possível fazer um histórico de ações que ele promoveu a favor de diretrizes que respeitassem o social e o meio ambiente, usando-o como um mote político sempre evidente. Os focos e propostas das campanhas mudavam, mas sempre conservaram um teor de preservação de recursos e aposta em investimentos de projetos com baixo impacto ambiental, segundo ela especialmente tópicos como "a destruição da Amazônia, o combustível limpo, o tratamento de esgotos e a despoluição dos rios, lagos e litorais, a implantação de uma lei ambiental, a transformação do modelo de transportes, a educação ambiental e a luta contra a corrida armamentista."

Em 1987, por exemplo, ele esteve presente na mídia diversas vezes por organizar manifestações como a "Fala Mulher", na luta contra a discriminação e a violência domestica. Houve também o protesto antinuclear denominado "Demonstração pela Paz", contra a inauguração das usinas de Angra dos Reis. Nesse mesmo ano ganhou destaque nas mídias cariocas com a campanha pela realização de testes de controles do grau de poluição dos ônibus. Suas campanhas televisivas nesse período de tempo entre as décadas de 80 e 90 utilizavam-se de slogans como "Salve a Amazônia", "é o futuro que vamos começar a criar", "o meio ambiente tem um defensor" onde geralmente os próprios candidatos faziam demonstrações de seus projetos ou das consequências da não preservação. Na "quem desmata mata" por exemplo o candidato Alfredo Sirkis se enterrou na praia, rodeado de lixo, para fortalecer a sua mensagem. Segundo Maria Fernanda, "os recursos do marketing verde estavam muito presentes nas falas e nas imagens assim como os recursos sonoros e visuais que exaltavam a natureza."

Na virada para o século XXI sua comunicação manteve essa mesma linha de diálogo, apostando em críticas ao atual modelo de desenvolvimento econômico e propondo práticas sustentáveis, apostando na pressão por leis que proteção aos animais e contra o mau uso dos recursos naturais. Destaca-se nesse momento também o uso da figura de Marina Silva, exMinistra do Meio Ambiente na gestão Lula, com um discurso onde "a ecologia e a economia podem andar juntas, mostrando como o partido está participando e ajudando as discussões sobre o meio ambiente em fóruns mundiais como o encontro MERCOSUL e o de Kopenhagne."

Em seu artigo Murad Sarney ainda afirma que:

A comunicação ecológica era mais presente no começo do partido, época em que os movimentos e a causa ecológica eram um tema novo dentro da disputa política. Apesar de nas últimas campanhas do Partido Verde a causa ter ficado um pouco menos evidente, ela nunca deixou de ser tema de nenhuma propaganda partidária do partido até hoje. Dessa forma podemos concluir que a hipótese foi confirmada, o Partido Verde utiliza as técnicas de comunicação do marketing verde para se fortalecer como marca institucional, trabalhando sempre por uma sociedade mais consciente e ambientalmente correta. (PARTIDO VERDE, 2016). 


\section{CONCLUSÃO}

Instaurar um partido, difundir sua ideologia e semear diretrizes necessariamente não é sinônimo de adesão pelos que são atingidos por tal mensagem. Na pesquisa exploratória vemos que em suas diretrizes o PV respeita e consolida-se como um partido sustentável. O partido por mais que venha ajustando sua comunicação e tenha folego em espalhar seus "mandamentos" sente a falta de maior adesão do eleitorado. O PV que outrora abordava questões muito ligadas ao meio ambiente hoje em dia se apega a uma comunicação que não defende sua ideologia sustentável nem tão pouco um discurso voltado a sanar os problemas do bicho homem.

Fazendo uma análise das pesquisas do IBOPE sobre as intenções de voto para as eleições de 2010, quando o PV ficou em terceiro lugar no primeiro turno - fato este inédito para o partido aqui no Brasil - é possível compreender melhor o perfil de quem votou no PV.

\begin{tabular}{|c|c|c|c|}
\hline Segmentos & Dilma & Serra & Marina \\
\hline SEXO & masculino & indiferente & feminino \\
\hline IDADE & $<30$ anos & 18 a 24 anos & 30 a 50 anos \\
\hline ESCOLARIDADE & $<$ ou $=$ nível médio & nível superior & nível médio ou superior \\
\hline REGIÃO & Nordeste & Sul & Norte / Centro-Oeste \\
\hline INTERIOR OU METRÓPOLE & indiferente & indiferente & capitais \\
\hline PORTE DE MUNICÍPIO & $<20$ mil habitantes & indiferente & > 100 mil habitantes \\
\hline RENDA & $<$ ou $=2$ salários mínimos & > 5 salários mínimos & > 5 saláriios mínimos \\
\hline PARTIDO & PT & PSDB e PMDB & outros partidos \\
\hline OCUPAÇÃO & conta própria & patrão ou empregado & patrão ou empregado \\
\hline RELIGIÃ̃O & católico & católico e sem religião & evangélicos e sem religião \\
\hline USO DE INTERNET & abaixo da média & na média & abaixo da média \\
\hline PARTICIPA PROGRAMAS SOCIAIS & acima da média & abaixo da média & abaixo da média \\
\hline ASSINA JORNAL & abaixo da média & acima da média & acima da média \\
\hline Segmentos & Indecisos & Branco/nulo & \\
\hline SEXO & feminino & indiferente & \\
\hline IDADE & $>40$ anos & $>40$ anos & \\
\hline ESCOLARIDADE & $<4^{\mathrm{a}}$ série Fundamental & nível médio & \\
\hline REGIÃO & Sul e Sudeste & Sudeste & \\
\hline INTERIOR OU METRÓPOLE & interior e entorno capitais & entorno das capitais & \\
\hline PORTE DE MUNICÍPIO & $<20$ mil habitantes & $>100$ mil habitantes & \\
\hline RENDA & $<$ ou $=2$ salários mínimos & 1 a 2 salários mínimos & \\
\hline PARTIDO & sem partido & sem partido & \\
\hline OCUPAÇÃO & não-ocupado & empregado & \\
\hline RELIGIÃ̃O & evangélicos & outras religiões & \\
\hline USO DE INTERNET & acima da média & abaixo da média & \\
\hline PARTICIPA PROGRAMAS SOCIAIS & abaixo da média & abaixo da média & \\
\hline ASSINA JORNAL & abaixo da média & acima da média & \\
\hline
\end{tabular}

Figura 01. PERFIL DO ELEITORADO - PRIMEIRO TURNO ELEIÇÕES 2010

Fonte: http://politica.estadao.com.br/

Vemos que os perfis dos eleitores do PV, em sua maioria, não são da classe C e D como no caso do Partido dos Trabalhadores (PT), nem concentrados nas regiões Sul e Sudeste, como no caso do PSDB. O PV encontra um nicho de eleitorado grande, porém não o suficiente para vencer uma eleição. Melhor seria se tivessem um discurso mais próximo da realidade do eleitorado de classe econômica menor e concentrado em regiões onde os impactos ambientais não são tão visíveis à realidade das pessoas, esta seria uma saída para um sucesso tangível em uma futura eleição.

Fugir da linguagem atual é uma possibilidade de melhoria para o sucesso do partido, visto que, um discurso sustentável pode ser construído permeando ainda mais a questão social, afinal, promover um melhoramento na sociedade é algo fundamentalmente humano o que traz proximidade com o público como defende Lipovetsky e Serroy (2011).

Visível é que o atual nível superficial das ideias comunicacionais estejam em demasia nas campanhas e discursos do PV aqui no Brasil. O mesmo promove em um de seus 12 mandamentos que a transformação da sociedade global se inicia localmente. Assim, entender e promover a melhoria não só do ambiente local e sim a evolução da própria comunidade de baixa renda é eixo promissor em uma reformulação do discurso.

Temos neste estudo o diagnóstico do uso não adequado à realidade atual do público brasileiro. O Partido Verde tem sucesso com um público mais instruído em regiões onde a 
questão sustentável afeta em maior grau a vida das pessoas, como mostramos na figura 1. Vemos que a possibilidade de crescimento do PV no Brasil é muito promissor, resta agora o partido entender os anseios de seu eleitorado a nível nacional, adequar seu discurso e promover uma mensagem próxima e pertinente à realidade do brasileiro.

\section{REFERÊNCIAS}

EVANGELISTA, Raquel Lobão; RUÃO, Teresa Augusta. Organizational Communication and Sustainability: studying European public campaigns. Observatorio (OBS*), v. 5, n. 3, 2011.

KOTLER, Philip; ARMSTRONG, Gary, KELLER, Kevin L. Administração De Marketing. Ed. 12. São Paulo. 2006.

LIPOVESKY, G.; SERROY, J. A Cultura-Mundo: resposta a uma sociedade desorientada. São Paulo: Companhia das Letras, 2011.

Partido Verde - História. Disponível em: <http://www.pvpe.com.br/institucional/historia/>. Acesso em: 16 de Junho de 2016.

REGO, F. T. "Tratado de comunicação organizacional e política." São Paulo: Pioneira, 2002.

REGO, F. T. "Marketing político e governamental". São Paulo, Editora Summus, 1985.

SARNEY, M. F. M.. "Partido Verde e o uso da Sustentabilidade como Estrategia de Marketing." (2009).

<http://repositorio.uniceub.br/bitstream/123456789/2174/2/20606434.pdf>. Acesso em: 26 de Julho de 2016. 